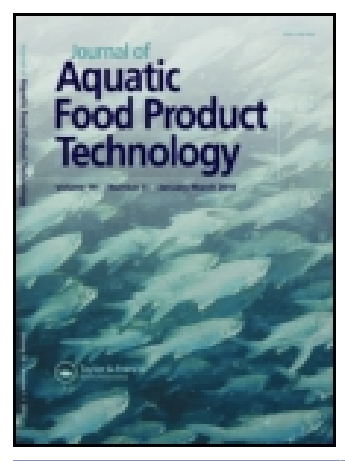

Journal of Aquatic Food Product Technology

ISSN: 1049-8850 (Print) 1547-0636 (Online) Journal homepage: http://www.tandfonline.com/loi/wafp20

\title{
Quality Evaluation of Alaska Pollock (Theragra chalcogramma) Roe by Image Analysis. Part I: Weight Prediction
}

Murat O. Balaban, Mélanie Chombeau , Bahar Gümüş \& Dilşat Cırban

To cite this article: Murat $O$. Balaban, Mélanie Chombeau, Bahar Gümüș \& Dilșat Cırban (2012) Quality Evaluation of Alaska Pollock (Theragra chalcogramma) Roe by Image Analysis. Part I: Weight Prediction, Journal of Aquatic Food Product Technology, 21:1, 59-71, DOI: 10.1080/10498850.2011.583377

To link to this article: http://dx.doi.org/10.1080/10498850.2011.583377

\section{曲 Published online: 23 Jan 2012.}

\section{Submit your article to this journal $๘$}

山 Article views: 87

Q View related articles 두

4 Citing articles: 1 View citing articles 


\title{
Quality Evaluation of Alaska Pollock (Theragra chalcogramma) Roe by Image Analysis. Part I: Weight Prediction
}

\author{
MURAT O. BALABAN, ${ }^{1}$ MÉLANIE CHOMBEAU, ${ }^{2}$ \\ BAHAR GÜMÜŞ, ${ }^{3}$ AND DILŞAT CIRBAN ${ }^{4}$ \\ ${ }^{1}$ Chemical and Materials Engineering Department, University of Auckland, \\ Auckland 1142, New Zealand \\ ${ }^{2}$ Agricultural Engineering School, ESITPA, Mont Saint Aignan, France \\ ${ }^{3}$ Faculty of Fisheries, Akdeniz University, Dumlupinar Bulvarı, Antalya, Turkey \\ ${ }^{4}$ Izmir Institute of Technology, Gülbahçe Köyü-Urla, İzmir, Turkey
}

\begin{abstract}
Roe is an important product of the Alaska pollock (Theragra chalcogramma) industry. About $31 \%$ of the value for all pollock products comes from roe, yet roe is $5 \%$ of the weight of the fish. Currently, the size (weight), color, and maturity of the roe are subjectively evaluated. The objective of this study was to develop methods to predict the weight of Alaska pollock roe based on its view area from a camera and to differentiate between single and double roes. One hundred and forty-two pollock roes were picked from a processing line in a Kodiak, AK plant. Each roe was weighed, placed in a light box equipped with a digital video camera, images were taken at two different angles from one side, then turned over and presented at two different angles again (four images for each roe). A reference square of known surface area was placed by the roe. The following equations were used to fit the view area $(X)$ versus weight $(Y)$ data: linear, power, and second-order polynomial. Error rates for the classification of roes by weight decreased significantly when weight prediction equations for single and double roes were developed separately. A "turn angle" method, a "box" method, and a "modified box" method were tested to differentiate single and double roes by image analysis. Machine vision can accurately determine the weight of pollock roe.

Practical Application Abstract: An image analysis method to accurately determine if pollock roe is a single or a double was developed. Then view area versus weight correlations were found for single and double roes that reduced incorrect weight classification rates to half that of human graders.
\end{abstract}

Keywords image processing, pollock roe, single, double, weight classification

\section{Introduction}

Alaska pollock is a large and important fishery for the United States. It accounts for more than one-third of total U.S fisheries landings and about 7\% of total U.S. ex-vessel value.

The authors would like to thank Westwards Seafoods, Inc.—especially Mr. Hiroyuki Kozuma, Vice President of Operations; Mr. Mitch Kilborn, General Manager; and Mr. Chris Sannito, QC Manager-for allowing the use of their plant and their fish for the study. Partial funding was provided by the University of Alaska Fairbanks.

Address correspondence to Murat O. Balaban, Department of Chemical and Materials Engineering, University of Auckland, 20 Symonds Street, Auckland 1142, New Zealand. E-mail: MuratKodiak@gmail.com 
In 2004, the revenues from roe accounted for $31 \%$ of all pollock products, while the volume of roe in the total pollock products was about 5\%. In 2003, the United States exported 21,729 metric tons of frozen Alaska pollock roe (National Marine Fisheries Service [NMFS], 2004). Approximately $96 \%$ of the frozen roe was exported to Japan and South Korea.

Currently, the quality evaluation of pollock roe is done by human graders based on a complicated set of criteria based on whether the roe is a single or double roe and based on its weight, intactness, color defects, and maturity (Table 1). Automation of quality evaluation is desirable for a more rapid, objective, and repeatable process (Balaban et al., 1994; Brosnan and Sun, 2002). Machine Vision (MV) systems have been developed and adapted for different products and are being used increasingly in the food industry for quality assurance to provide a high level of flexibility and repeatability at relatively low cost (Gunasekaran, 1996; Balaban and Odabaş1, 2006). MV has been applied to many foods

Table 1

Example of quality grade scale of double and single roes, as determined by the Kodiak plant

\begin{tabular}{|c|c|c|c|c|}
\hline \multicolumn{3}{|c|}{ Condition } & \multicolumn{2}{|c|}{ Size } \\
\hline & & Grade & Pair & Single \\
\hline \multirow{19}{*}{$\begin{array}{c}\text { Full shape roe } \\
\text { without } \\
\text { damage }\end{array}$} & Mature roe & $3 \mathrm{~L}$ & $250 \mathrm{~g}$ up & $125 \mathrm{~g}$ up \\
\hline & & $2 \mathrm{~L}$ & $180-250 \mathrm{~g}$ & $90-125 \mathrm{~g}$ \\
\hline & & $\mathrm{L}$ & $130-180 \mathrm{~g}$ & $65-90 \mathrm{~g}$ \\
\hline & & M & $80-130 \mathrm{~g}$ & $40-65 \mathrm{~g}$ \\
\hline & & S & $50-80 \mathrm{~g}$ & $25-40 \mathrm{~g}$ \\
\hline & & SS & $30-50 \mathrm{~g}$ & $15-25 \mathrm{~g}$ \\
\hline & & WF-L & $150 \mathrm{~g}$ up & $75 \mathrm{~g}$ up \\
\hline & & WF-M & $30-150 \mathrm{~g}$ & $15-75 \mathrm{~g}$ \\
\hline & & $\mathrm{MX}$ & $30 \mathrm{~g}$ under & $15 \mathrm{~g}$ under \\
\hline & & $\begin{array}{l}\text { Dark color, green spot, freez } \\
\text { more than } 10 \%\end{array}$ & zer burn, dar & triped line \\
\hline & Over-mature & $\mathrm{OA}$ & $50 \mathrm{~g}$ up & $25 \mathrm{~g}$ up \\
\hline & & Less than $10 \%$ of eyed egg & & \\
\hline & & $\mathrm{OB}$ & $20-40 \mathrm{~g}$ & $10-20 \mathrm{~g}$ \\
\hline & & Less than $30 \%$ of eyed egg & & \\
\hline & Immature & $\mathrm{IM}$ & $40 \mathrm{~g}$ up & $20 \mathrm{~g}$ up \\
\hline & & NO DAMAGE & & \\
\hline & & IMS & $20-40 \mathrm{~g}$ & $10-20 \mathrm{~g}$ \\
\hline & & Include freezer burn IM & & \\
\hline & & Cut roe & & \\
\hline \multirow[t]{4}{*}{ Mature roe } & & CA & $30 \mathrm{~g}$ up & $15 \mathrm{~g}$ up \\
\hline & & Cut less than $20 \%$ include c & cut mature $\mathrm{V}$ & \\
\hline & & $\mathrm{CB}$ & $30 \mathrm{~g}$ up & $15 \mathrm{~g}$ up \\
\hline & & Cut $20-70 \%$ include immatu & ture & \\
\hline \multirow[t]{2}{*}{ Overmature } & & $\mathrm{COA}$ & 40 g up & $20 \mathrm{~g}$ up \\
\hline & & Cut less than $20 \%$ of OA & & \\
\hline
\end{tabular}


including quality grading of fruits where it is used to evaluate the quality attributes of size, color, stem location, and detection of blemishes (Blasco et al., 2003). MV has also been used for the quality analysis of meat, fish, pizza, cheese, and bread (Brosnan and Sun, 2004; Tan, 2003). Further, it is possible to determine the weight and volume of different foods such as ham, shrimp, oysters, rainbow trout, and salmon (Du and Sun, 2006; Eifert et al., 2006; Damar et al., 2006; Gümüş and Balaban, 2010; Balaban et al., 2010).

Bekhit et al. (2009) evaluated the color parameters (lightness $L^{*}$, redness a*, yellowness $\mathrm{b}^{*}$, chroma $\mathrm{C}^{*}$, and hue $\mathrm{h}^{*}$ ) and spectral surface reflectance of raw and processed roes from the following species: chinook salmon, hoki, southern blue whiting, hake, blue warehou, and barracouta. Beatty (1993), Beatty et al. (1993), Croft et al. (1996), and Kurnianto et al. (1999) developed a two-dimensional contour shape analysis method for automated herring roe quality grading by computer vision. Shape defects such as "probiscus" and "broken end" were detected. Herring roe has a single skein (sac that holds individual eggs), compared to either a single or a double skein for pollock roe. In addition, there are color-based defects that need to be detected in pollock roe (Bledsoe and Rasco, 2006).

The automation of quality evaluation of pollock roe would require the following steps: the determination of shape (single or double roe, intactness), the determination of weight, the determination of the maturity of the roes, and the quantification of visual defects such as greening. These steps are interconnected, as shown in Table 1. For example, the weight classification depends on single or double roes, on intactness, and on maturity.

MV grading to determine the quality of Alaska pollock roe is desirable to increase the reliability and uniformity of grading, with the possibility to non-destructively analyze several parameters simultaneously. As a first step toward this end, the objectives of this study were (a) to develop weight versus view area correlations for Alaska pollock roe with the aim of automated sorting by weight using MV and (b) to develop and test image analysis methods to differentiate between single and double roes.

\section{Materials and Methods}

\section{Roe}

One hundred and forty-two pollock roes were used for this study. The roes were already graded by plant personnel based on criteria shown in Table 1. They were temporarily removed from the processing line in a Kodiak, AK plant, weighed, and their image obtained by placing them in a light box defined by Luzuriaga et al. (1997). The roe was then returned to the processing line. The roes were chosen at random within a grade, and we tried to have about 10 roes per quality grade, depending on availability.

\section{Weighing and Imaging}

The scale to measure the weight was Mettler Toledo PB 3002-S (Colombus, OH, USA), with a maximum capacity of 3,100 g, and with an accuracy of $0.1 \mathrm{~g}$. Each pollock roe was weighed, and then its picture was taken. A light box, designed and built by the researchers (Luzuriaga et al., 1997)—with the dimensions 122-cm high, 61-cm wide, and 46-cm deep-was placed in the plant, close to the roe processing line. The light box had D65 illumination using fluorescent bulbs with a Color Retention Index of 0.98. The door of the light box was closed during image acquisition to eliminate interference from ambient light. The roe was placed under a DFK 31BF03 video camera (The Imaging Source, Charlotte, NC, USA) with a $1024 \times 768$ pixel resolution and an IEEE1394 interface. It had 
Table 2

Settings of the video camera

\begin{tabular}{lc}
\hline Setting & Specifications \\
\hline Brightness & 32 \\
Hue & 169 \\
Saturation & 102 \\
Exposure & -2 \\
Gamma & 10 \\
Contrast & 585 \\
White balance & 56 \\
\hline
\end{tabular}

a Tamron F: 6-12 mm, 12VM 612 lens (Tamron USA, Commack, NY, USA). The camera settings were calibrated by minimizing the cumulative error for 8 colors (red, green, blue, yellow, magenta, cyan, black, white) that correspond to the eight corners of the Red Green Blue (RGB) color space (Table 2). Reference colors (Color Checker Classic, X-rite Inc., Grand Rapids, MI, USA) were used for this.

A reference square of $5-\mathrm{cm} \times 5-\mathrm{cm}$ was cut from a black carton. This square was used as a reference for size to calibrate image properties during analysis and was included in every picture by placing it inside the light box (Figure 1). Four images were acquired for the same roe in the light box, to compare if the angle and side of the roe had an impact on the view area (Figure 2). Images were taken from two different angles for the roe, then it was flipped to the other side, and the process was repeated. The LensEye software (Engineering and CyberSolutions, Gainesville, FL, USA) was used to calculate the view area of each roe calibrated by the reference square. Since the surface area of the reference square was $25 \mathrm{~cm}^{2}$ :

$$
\text { Roe View area }\left(\mathrm{cm}^{2}\right)=\text { Roe pixels/Reference square pixels } \times 25
$$

\section{Image Analysis}

After segmentation (differentiation of the roe from the background) by using threshold Red, Green, Blue (RGB) values, the perimeter of the roe was determined, and equidistant points on it were taken to form an irregular polygon of 50 vertex points. The software to accomplish this was developed using Visual Basic 6 (Microsoft, Redmond, WA, USA).
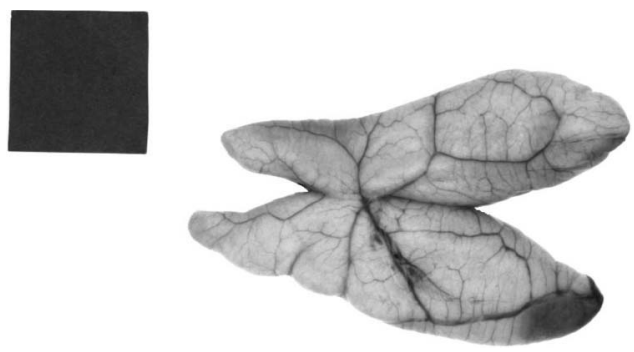

Figure 1. Image of Alaska pollock roe taken in the light box, with the reference square. 


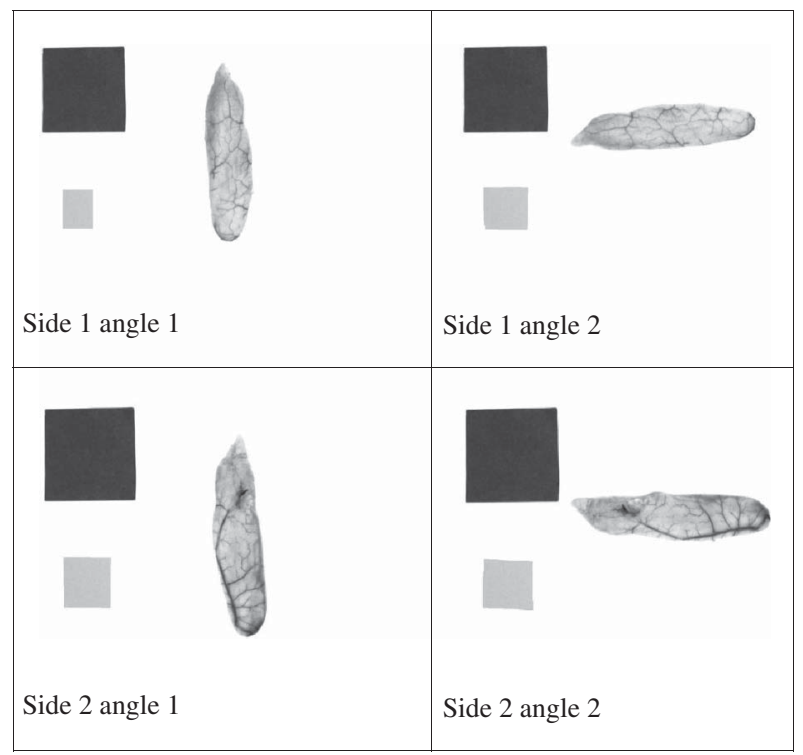

Figure 2. Four images taken to determine the impact of side and angle on the view area.

\section{Regression Analysis}

The following correlations between the view area and weight were tried, based on previous experience with other foods (Balaban et al., 1994, 2010; Gümüş and Balaban, 2010): linear, power, and second-order polynomial.

$$
\begin{aligned}
& \text { Linear: } \mathrm{Y}=\mathrm{A}+\mathrm{BX}, \\
& \text { Power: } \quad \mathrm{Y}=\mathrm{AX}^{\mathrm{B}}, \\
& \text { Polynomial fitting: } \mathrm{Y}=\mathrm{C}_{0}+\mathrm{C}_{1} \mathrm{X}+\mathrm{C}_{2} \mathrm{X}^{2}
\end{aligned}
$$

In the equations above, $\mathrm{Y}=$ weight $(\mathrm{kg}), \mathrm{X}=$ view area $\left(\mathrm{cm}^{2}\right), \mathrm{A}, \mathrm{B}, \mathrm{C}_{\mathrm{i}}$ are coefficients. The coefficients and the $R^{2}$ for the fit were calculated. Statistica software (Statsoft, Tulsa, OK, USA) was used for regression analyses. For the coefficients, the $95 \%$ confidence intervals were calculated.

\section{Development of Single Versus Double Roe Differentiation Methods}

Three image analysis methods were developed and tested for the differentiation between a single and a double roe. For the purposes of this study, they were called the "turn angle" method, the "box" method, and the "modified box" method.

"Turn Angle" Method. This is a common method in image analysis for shape recognition. For example, Han and Tewfik (1996) used this method to recognize different crab species. The irregular polygon with 50 vertices described above was used. For a given set of three consecutive vertex points, the following was performed:

- Determine the line formed by the first two vertex points.

- Calculate the angle formed between this line and the third vertex point. A positive angle was considered as going counterclockwise. 
- Repeat this for all vertex points.

- By trial-and-error, determine a threshold turn angle (set at 90 degrees in this study) to identify the double roe.

The expectation of this method was that for a single roe, there would be mostly smallangle changes, and the angle changes would be mostly going toward the same direction (e.g., counterclockwise). Examples of two single roes are shown in Figures $3 \mathrm{a}$ and b. In contrast, a double roe has a drastic change of angle in one (vertex point 40, Figure 3a) or two (vertex points 7 and 30, Figure 3b) points at the perimeter corresponding to the point(s) where the two halves meet in a V shape. If there was at least one 90-degree or higher turn, then the roe was deemed as a double.

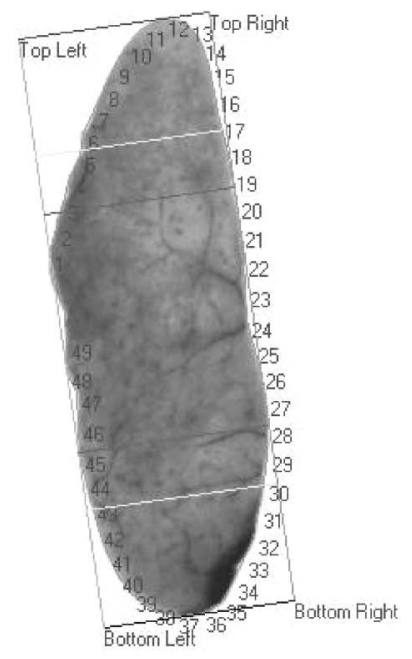

(A)

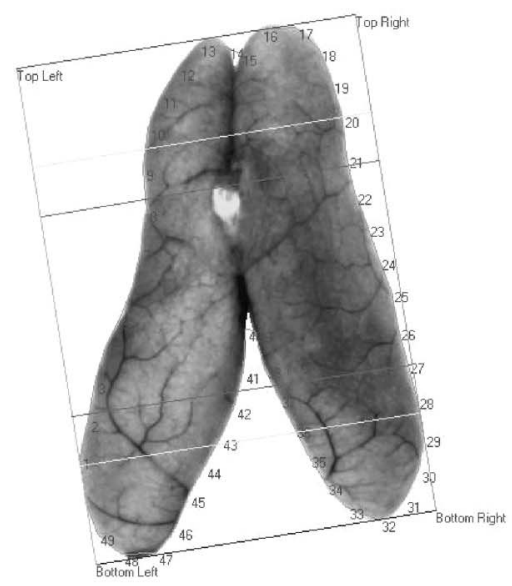

(a)

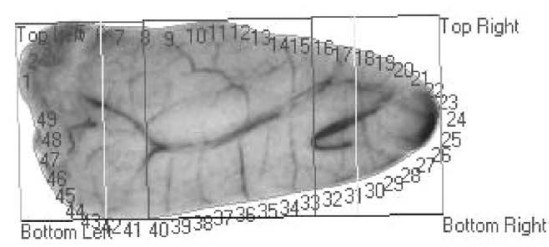

(B)

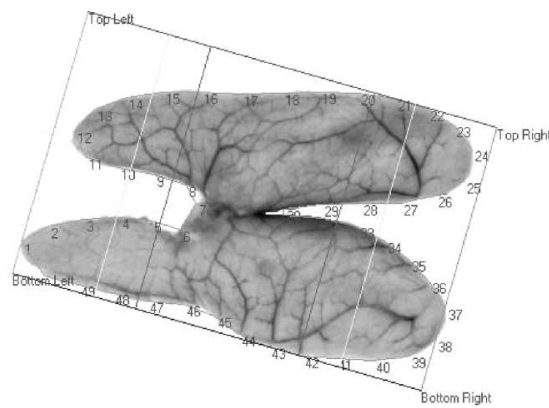

(b)

Figure 3. Examples of single and double roes, with the "box" method shown, and the perimeter points indicated. 
The "Box" Method. The "box" method followed the steps below to determine if a roe was a single or a double:

- Fit the best (i.e., minimum area) rectangle around the roe. The procedure is described by Balaban et al. (2010).

- By comparing the length and width of the rectangle, determine the orientation of the roe.

- Draw lines perpendicular to the long axis, starting from both ends and moving inward by a pre-determined percentage of the length (20 and 30\% in this study, found by trial-and-error). An example of the boxes drawn and lines described above for single and double roes is given in Figure 3. The number of times these four lines intersected the polygon were counted.

The expectation was that for a double roe, at least one of these lines would intersect the perimeter polygon in four locations, while for the single roe none of the lines would have four intersection points with the perimeter polygon.

Preliminary analysis showed that for a double roe, if the two halves of the roe were separated enough, then the "width" would be more than the "length," and this would result in incorrect orientation with the four lines intersecting in two places, not four. This error would only occur for some of the double roes; single roes would be correctly identified by this method.

The "Modified Box" Method. The ratio of the width/length of the best rectangle fitted around each roe was calculated. If the ratio was greater than 1 , it was inverted to assure that all ratios were between 0 and 1 . An analysis of the ratios revealed that all the single roes had the ratio values below 0.45 in this study. Also, all of the roes with ratios higher than 0.65 were double roes. This left only roes with ratios between 0.45 and 0.65 . Only these roes were analyzed using the "box" method described above to determine if they were a double or a single. Once the roe was correctly identified as single or double, then the appropriate equation was used for that type to estimate the weight.

\section{Results and Discussion}

\section{Effect of Images from Different Sides and Angles for the Same Roe}

The average view area of each roe from its four images was calculated. The frequency distributions of the percent standard deviation for singles and doubles are shown in Figure 4. The average percent standard deviation was around $2.5 \%$ for the roes. Based on these, it can be concluded that the orientation angle or the side of the roe causes no significant deviation in the view area calculation using a MV system. This is also shown in Figure 5, where the view areas based on angle 1 or angle 2 for the sides are located mostly on the 45-degree line. Therefore, the orientation of the roe was not important in finding a correlation between the view area and the weight.

\section{Correlation of Weight Versus View Area}

Linear (Equation 2), power (Equation 3), and second-order polynomial (Equation 4) fits were done for single roes only, double roes only, and for all roes (single and double) combined. The results are presented in Table 3 . The purpose of the combination of single 


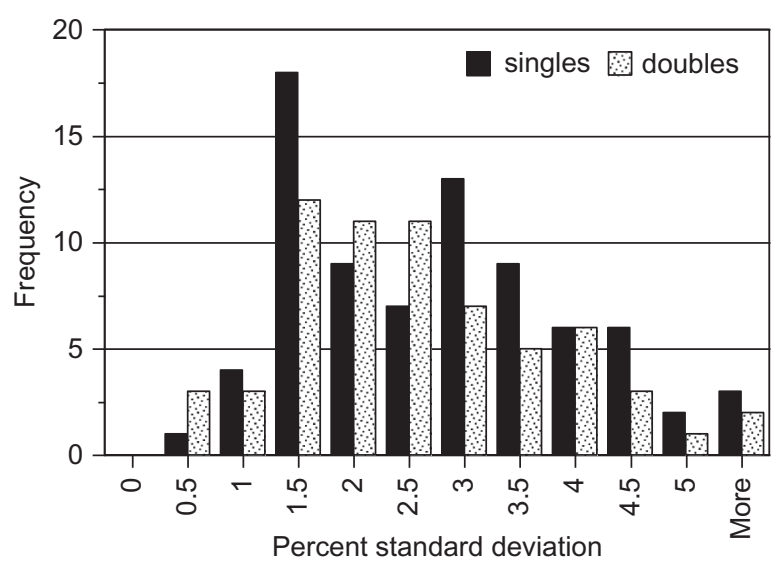

Figure 4. Frequency distribution of percent standard deviations for single and double roes: view areas of four images of the same roe.

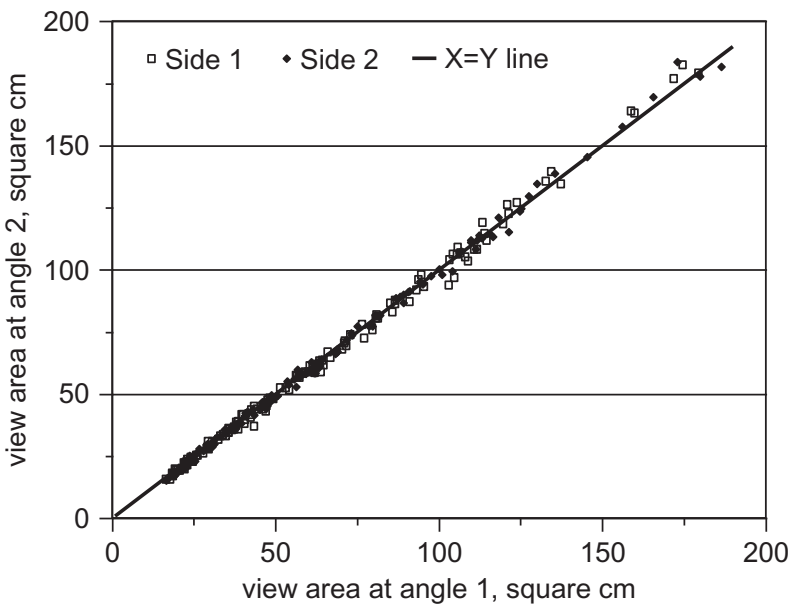

Figure 5. Effect of the side and angle of image on view area.

and double roes for analysis was to determine the level of weight prediction error of this simplified approach. Ignoring whether a roe is a double or single for weight prediction would simplify operations. For the combined data, the polynomial fit had higher $R^{2}(0.974)$, while the linear and power fits had similar $R^{2}(0.969)$. The plot of experimental weights and their predictions for all roes combined is shown in Figure 6.

The purpose for the separate fits for single and double roes was to see if there was a significant difference between the prediction equations. The $95 \%$ confidence intervals of the following parameters between single roe and double roe fits did not overlap: parameter A for the linear fit (Equation 2), parameter B for the power fit (Equation 3), and parameter $\mathrm{C}_{2}$ for the second-order polynomial fit (Equation 4). Therefore, all three equations would have to be applied separately to single and double roes. From Table 3, the polynomial fit had the highest $R^{2}$ for single roes $(0.976)$, and the power fit was the best for double roes $\left(R^{2}=0.987\right)$. Figure 7 shows separate fits for single and double roes, with experimental data also displayed. 


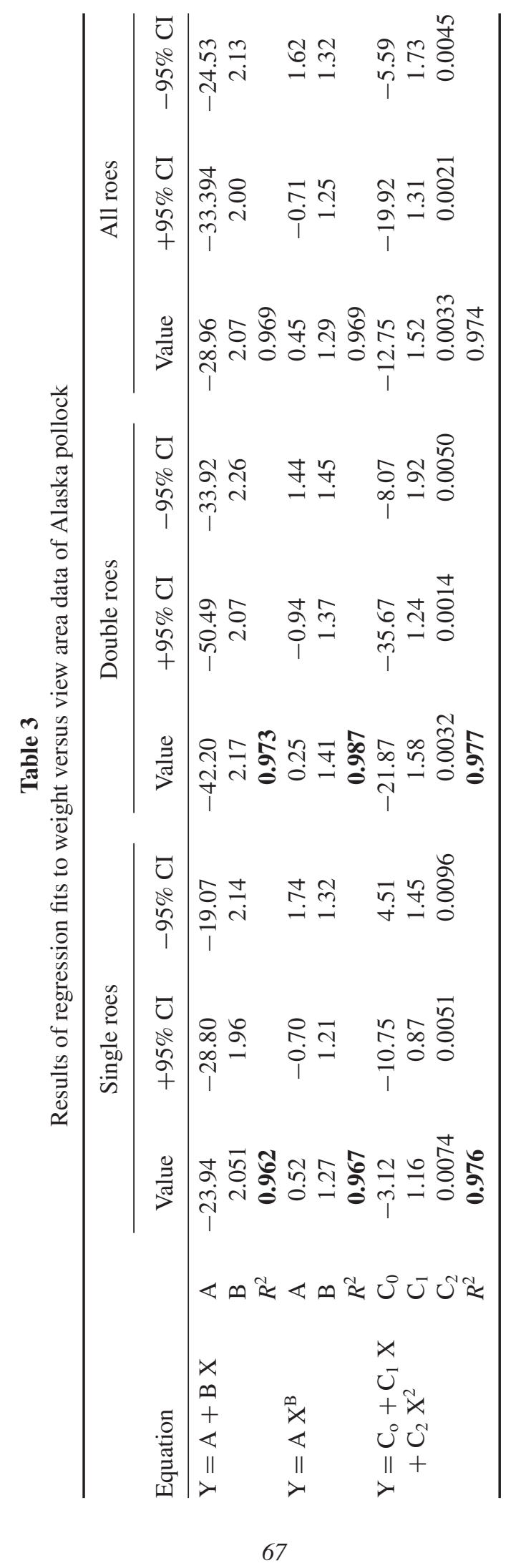




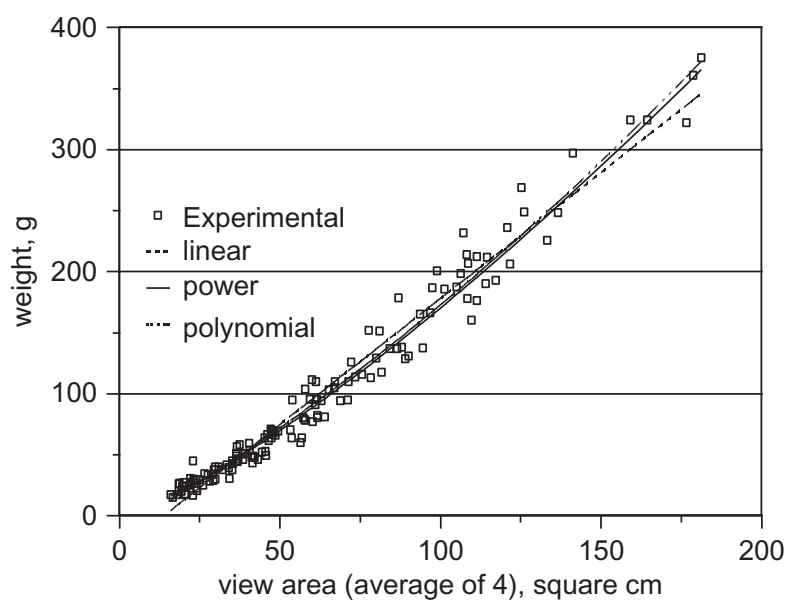

Figure 6. Comparison between different equations to predict the weight of roes, with single and double roes combined.

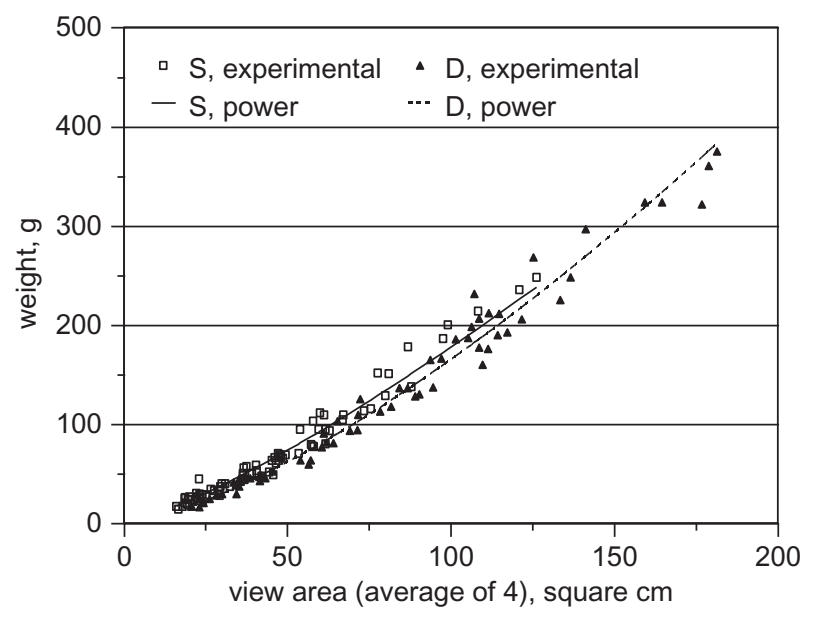

Figure 7. Comparison between single (S) and double (D) roes, when fitted separately.

\section{Effect of Double and Single Roes on Weight Prediction Error}

Since both the weight of each roe and its grade was known, it was possible to check if it was classified correctly by human graders according to Table 1. As shown in Table 4, human graders incorrectly classified 18 roes out of 142 , with an error rate of about $13 \%$. The incorrect classification of single roes ( 7 out of 78 roes, or about $9 \%$ ) was less than that of double roes (11 out of 64 roes, or $17 \%$ ).

Next, the power and polynomial fit weight predictions developed by combining all roes were tested for their error rates. The result is shown in Table 4. The power fit had an error rate for all roes of about $13 \%$, or the same as human graders, while the polynomial fit had a $14 \%$ error rate. Evidently, the combination of single and double roes to develop predictive equations does not bring an improvement over human graders. Therefore, different predictive equations need to be developed for single and double roes. The error rates of these equations are also shown in Table 4. Using the power fit for doubles resulted in an incorrect weight classification of 5 roes out of 64 doubles (7.7\% error), 
Table 4

Error rates in grading of the pollock roe by weight

\begin{tabular}{|c|c|c|c|c|c|c|}
\hline & & \# of roes & Wrong grade & $\%$ error & & \\
\hline \multirow{5}{*}{$\begin{array}{l}\text { Human } \\
\text { graders }\end{array}$} & All roes & 142 & 18 & 12.68 & & \\
\hline & D only & 64 & 11 & 17.19 & & \\
\hline & S only & 78 & 7 & 8.97 & & \\
\hline & & & \multicolumn{2}{|c|}{ Power fit } & \multicolumn{2}{|c|}{ Polynomial fit } \\
\hline & & & Wrong grade & $\%$ error & Wrong grade & $\%$ errol \\
\hline \multirow{5}{*}{$\begin{array}{l}\text { All roes } \\
\text { combined }\end{array}$} & All roes & 142 & 18 & 12.68 & 20 & 14.08 \\
\hline & D only & 64 & 12 & 18.75 & 13 & 20.31 \\
\hline & S only & 78 & 6 & 7.69 & 7 & 8.97 \\
\hline & & & \multicolumn{2}{|c|}{ Power fit } & \multicolumn{2}{|c|}{ Polynomial fit } \\
\hline & & & Wrong grade & $\%$ error & Wrong grade & $\%$ errol \\
\hline \multirow{3}{*}{$\begin{array}{c}\text { Separate fits, } \\
D \text { and } S\end{array}$} & All roes & 142 & 9 & 6.34 & 11 & 7.75 \\
\hline & D only & 64 & 5 & 7.81 & 8 & 12.5 \\
\hline & S only & 78 & 4 & 5.13 & 3 & 3.85 \\
\hline
\end{tabular}

and using the polynomial fit for single roes resulted in incorrect classifications of 3 out of 78 single roes (3.9\% error). This approach reduces the error rate to half of the human error rate.

The above results made clear that an automated weight prediction method needed to be able to differentiate between single and double roes to correctly apply the appropriate prediction equation. The next step was to develop and test methods to identify single and double roes by image analysis.

\section{Error Rates of Methods to Differentiate Between Single and Double Roes}

Typical results for the "turn angle" method for single and double roes are shown in Figure 8. These are the results for the roes displayed in Figure 3. Because of at least one $\mathrm{V}$ shape in the perimeter of the double roe, one can observe large peaks (large changes in turn angle) for the double roes, either in the positive or in the negative region of the Y-axis. In contrast, single roes had smaller changes in turn angles, without large peaks in Figure 8. However, this was not always the case. If a single roe had a sharp end, this resulted in a large turn angle, and it was misclassified as a double by this method. Also, there were cases where the double roe was misclassified as a single. These error rates are presented in Table 5.

The "box" method correctly identified all single roes, but there were cases where it misclassified a double roe as single. This occurred when the axial "width" of the roe as a whole was greater than its axial "length." This caused the software to incorrectly orient the roe, resulting in misclassification. The misclassification rate of the "box" method is also shown in Table 5.

To reduce the misclassification rate, the "box" method was modified as described in the Materials and Methods section. This involved calculation of the ratio of the width to length of the box around the roe. In this study, all roes with a ratio of 0.45 or below were single roes. Also, all roes with a ratio of 0.65 or higher were double roes. Between 0.45 and 0.65 , 


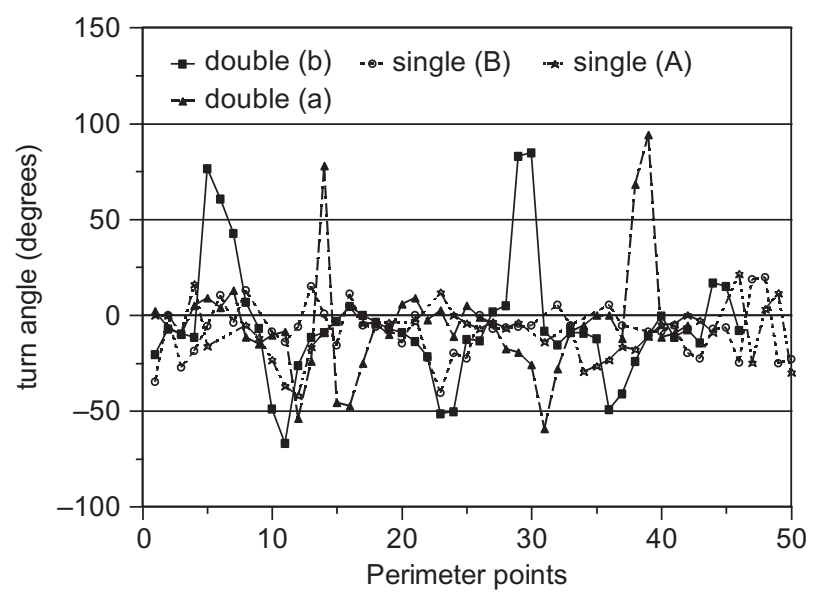

Figure 8. MV separation of single and double roes using the "turn angles" method.

Table 5

Error rates for the determination of single and double roes

\begin{tabular}{|c|c|c|c|c|c|}
\hline & \multirow[b]{2}{*}{ \# roes } & \multicolumn{2}{|c|}{ "Turn angles" method } & \multicolumn{2}{|c|}{ "Box" method } \\
\hline & & Wrong predictions & $\%$ error & Wrong predictions & $\%$ error \\
\hline \multirow{4}{*}{ Single } & S1 A1: (78) & 3 & 3.8 & 0 & 0 \\
\hline & S1 A2: (78) & 5 & 6.4 & 0 & 0 \\
\hline & S2 A1: (77) & 4 & 5.2 & 0 & 0 \\
\hline & S2 A2: (77) & 4 & 5.2 & 0 & 0 \\
\hline \multirow[t]{4}{*}{ Double } & S1 A1: (63) & 2 & 3.2 & 3 & 4.8 \\
\hline & S1 A2: (63) & 4 & 6.3 & 1 & 1.6 \\
\hline & S2 A1: (63) & 1 & 1.6 & 3 & 4.8 \\
\hline & S2 A2: (63) & 2 & 3.2 & 0 & 0 \\
\hline
\end{tabular}

$\mathrm{S}=$ Side $; \mathrm{A}=$ Angle

there were single roes and double roes. These were identified using the "box" method. Since the cases where the "box" method failed involved double roes that had the ratios much higher than 0.65 , this modified method resulted in an error rate of zero.

Therefore, the prediction of the weight of the pollock roe, which is only a part of the quality evaluation, can be accomplished automatically using the following steps:

- Use the "modified box" method in image analysis to determine if the roe is single or double.

- Based on the above, use the appropriate equation (polynomial fit for singles, power fit for doubles) to predict the weight based on the calibrated view area of the roe, obtained from a MV system.

\section{Conclusion and Recommendations}

The method developed in this study to differentiate between a single and double roe, combined with their predictive equations, can determine pollock roe weight with an error rate 
which is half that of the human graders. Since weight is only one part of the quality evaluation, the next steps in completing the automation of quality evaluation are: quantification of cut ends, quantification of color defects, and determination of the maturity of the roe. Upcoming studies in this series will address these steps.

\section{References}

Balaban, M. O., Bergmann, Y., Yeralan, S., and Otwell, W. S. 1994. Determination of count and uniformity ratio of shrimp by machine vision. J. Aquat. Food Prod. T. 3(3): 43-58.

Balaban, M. O., Gulgun, F. U. S., Soriano, M. G., and Ruiz, E. G. 2010. Using image analysis to predict the weight of Alaska salmon of different species. J. Food Sci. 75(3): E157-E162.

Balaban, M. O., and Odabaş1, A. Z. 2006. Measuring color with machine vision. Food Technol. 60: 32-36.

Beatty, A, Gosine R. G., and de Silva, C. W. 1993. Recent developments in the application of computer vision for automated herring roe assessment. IEEE Pac. Rim 2: 698-701.

Beatty, D. A. 1993. 2-D contour shape analysis for automated herring roe quality grading by computer vision. Unpublished master's thesis, University of British Columbia, Vancouver, British Columbia, Canada.

Bekhit, A. E. A., Morton, J. D., Dawson, C. O., and Sedcole, R. 2009. Optical properties of raw and processed fish roes from six commercial New Zealand species. J. Food Eng. 91: 363-371.

Blasco, J., Aleixos, N., and Molto, E. 2003. Machine vision system for automatic quality grading of fruit. Biosyst. Eng. 85(4): 415-423.

Bledsoe, G., and Rasco, B. 2006. Caviar and fish roe. In: Handbook of Food Science, Technology, and Engineering. Hui, Y. H. (Ed). Boca Raton, FL: CRC Press.

Brosnan, T., and Sun, D. W. 2002. Inspection and grading of agricultural and food products by computer vision systems-A review. Comput. Electron. Agr. 36: 193-213.

Brosnan, T., and Sun, D. W. 2004. Improving quality inspection of food products by computer vision-A review. J. Food Eng. 61: 3-16.

Croft, E. A., de Silva, C. W., and Kurnianto, S. 1996. Sensor technology integration in an intelligent machine for herring roe grading. IEEE-ASME T. Mech. 1(3): 204-215.

Damar, S., Yağız, Y., Balaban, M.O., Ural, S., Oliveira, A. C. M., and Crapo, C. A. 2006. Prediction of oyster volume and weight using machine vision. J. Aquat. Food Prod. T. 15(4): 3-13.

Du, C. J., and Sun, D. W. 2006. Estimating the surface area and volume of ellipsoidal ham using computer vision. J. Food Eng. 73(3): 260-268.

Eifert, J. D., Sanglay, G. C., Lee, D.-J., Summer, S. S., and Pierson, M. D. 2006. Prediction of raw produce surface area from weight measurement. J. Food Eng. (74): 552-556.

Gümüş, B., and Balaban, M. O. 2010. Prediction of the weight of aquacultured rainbow trout (Oncorhynchus mykiss) by image analysis. J. Aquat. Food Prod. T. 19: 227-237.

Gunasekaran, S. 1996. Computer vision technology for food quality assurance. Trends Food Sci. Tech. 7: 245-256.

Han, K. J., and Tewfik, A. H. 1996. Expert computer vision based crab recognition system. Proceedings of the International Conference on Image Processing. Lausanne, Switzerland. 16-19 Sep 1996. vol 2:649-652. DOI: 10.1109/ICIP.1996.560961

Kurnianto, S., de Silva, C. W., Croft, E. A., and Gosine, R. G. 1999. Intelligent automation of herring roe grading. In: Intelligent Adaptive Control: Industrial Applications. Jain, L. C., and de Silva, C. W. (Eds). Boca Raton, FL: CRC Press.

Luzuriaga, D., Balaban, M. O., and Yeralan, S. 1997. Analysis of visual quality attributes of white shrimp by machine vision. J. Food Sci. 62(1): 1-7.

National Marine Fisheries Service. 2004. Fisheries of the United States 2003. Silver Spring, MD: U.S. Department of Commerce.

Tan, J. 2003. Meat quality evaluation by computer vision. J. Food Eng. 61: 27-35. 